\title{
The cat scratch colon sign in a patient with chronic cholestasis
}

Cat scratch colon, first described by McDonnell et al. [1], is a rare colonoscopic finding, with only a few articles published in the literature. The patients in these reports have been predominantly female and the finding has been commonly associated with collagenous colitis or diversion colitis. The main proposed causative mechanism is barotrauma [1-3], and until now, the sign has been considered to be a manifestation of certain relatively benign conditions. However, as we report here, other conditions, such as chronic cholestasis in our case, may also be associated with the cat scratch sign.

A 50-year-old man was referred to our clinic for evaluation of extrahepatic cholestasis. The patient had a colonoscopic examination while undergoing tests as part of routine colorectal cancer screening. During the colonoscopy we noticed bright red, linear markings in the ascending colon, similar to the cat scratch colon sign ( Fig. 1, 2).

The other colon segments were normal. Based on all the results of the investigations, the patient was diagnosed as having cholangiocellular carcinoma, which was deemed to be the cause of his extrahepatic cholestasis.

Chronic cholestasis can impair vitamin absorption, particularly the lipid-soluble vitamins (A, D, E, and $\mathrm{K}$ ). The epithelial disruption and a tendency to bleed in the colon, resulting from deficiency of vitamins $\mathrm{A}$ and $\mathrm{K}$, respectively, may lead to a vulnerable state and cat scratch colon. Our patient's prothrombin time was prolonged, which was corrected with vitamin $\mathrm{K}$ administration. The levels of the other lipid-soluble vitamins were also below normal (data not shown). Moreover, there is a growing body of published evidence that chronic cholestasis can impair the

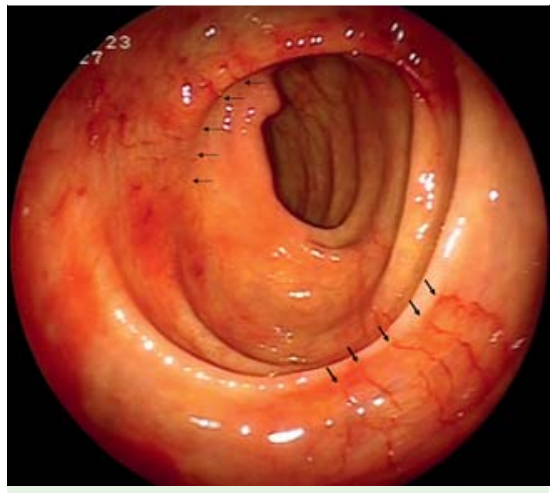

Fig. 1 Cat scratch sign in the ascending colon.

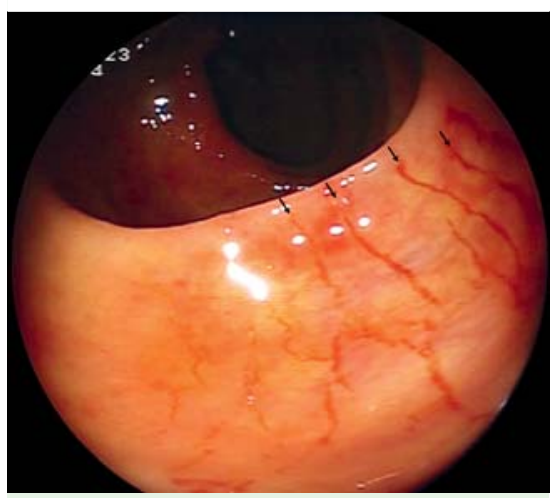

Fig. 2 Close up view of the same lesion.

gut's barrier function. In the reports in the literature it has been observed that obstructive jaundice in humans generates huge intestinal oxidative stress, which may disrupt the intestinal barrier function $[4,5]$. Therefore we think that chronic cholestasis and its complications may also be one of the conditions responsible for the cat scratch colon sign.

\section{Competing interests: None}

Endoscopy_UCTN_Code_CCL_1AD_2AJ
T. Purnak ${ }^{1}$, E. Ozaslan ${ }^{1}$, A. Yildiz ${ }^{1}$, C. Efe ${ }^{2}$

1 Department of Gastroenterology, Numune Education and Research Hospital, Ankara, Turkey

2 Department of Internal Medicine, Numune Education and Research Hospital, Ankara, Turkey

\section{References}

1 McDonnell WM, Loura F, Pointon MJ et al. Cat scratch colon. Endoscopy 2007; 39: 459461

2 Katsinelos P, Kountouras J, Chatzimavroudis $G$ et al. "Cat scratch" colon: an impressive but innocent endoscopic finding. Endoscopy 2007; 39: 1026

3 Baudet JS, Diaz-Bethencourt D, Arguinarena $X$ et al. Cat scratch colon is caused by barotrauma secondary to insufflation during colonoscopy. Endoscopy 2008; 40: 878

4 Assimakopoulos SF, Thomopoulos KC, Patsoukis $\mathrm{N}$ et al. Evidence for intestinal oxidative stress in patients with obstructive jaundice. Eur J Clin Invest 2006; 36: 181 - 187

5 Parks RW, Stuart Cameron CH, Gannon CD et al. Changes in gastrointestinal morphology associated with obstructive jaundice. J Pathol 2000; 192: 526-532

\section{Bibliography}

DOI $10.1055 / \mathrm{s}-0029-1243983$

Endoscopy 2010; 42: E117

(c) Georg Thieme Verlag KG Stuttgart · New York . ISSN 0013-726X

\section{Corresponding author}

\section{T. Purnak}

Department of Gastroenterology

Ankara Numune Education and Research Hospital

Talatpasa Bulvari

Samanpazari 06100

Sihhiye

Ankara

Turkey

Fax: +90-312-3125026

purnakt@yahoo.com 